\title{
FÓSCOLO: O POETA DOS TÚMULOS
}

\author{
LUIGGI CASTAGNOLA
}

\section{1 - Trajetória existencial e sentimental de Fóscolo.}

Hugo Fóscolo começou sua viagem corporal nesta terra em Zante ('), ilha do mar Jônio, onde nasceu em 1778, e a terminou nas ilhas britânicas, falecendo em Londres, em 1827. Passou ràpidamente pela Dalmácia, Suíça e França, mas fêz uma longa parada na Itália, tornando-se uma das figuras mais empolgantes da história literária e civil daquele pais $\left(^{2}\right)$.

Nossos tempos de triunfante hestética idealista costumam dar pouca importância à vida dos autores. Julgamos, no entanto, ser por vêzes impossível compreender a gênese da mensagem original de certos poetas sem lhes conhecer, suficientemente, a trajetória existencial. Entre êsses poetas colocamos Hugo Fóscolo.

Filho de pai veneziano e de mãe grega $\left({ }^{3}\right)$, passou na ilha natal a sua infância. Bem cedo, porém, começou sua peregrinação entre os homens. Indo seu pai a trabalhar, na qualidade de médico, no hospital de Spálato, na Dalmácia ( $\left.{ }^{4}\right)$, Fóscolo acompanhou-o e estudou por algum tempo no seminário daquela cidade. Após a morte do pai (1788), voltou a Zante e, em 1792, transferiu-se com a mãe e os irmãos $\left(^{(5)}\right.$ para Veneza, que amou como sua pátria de adoção ${ }^{(6)}$. Guardou sempre, todavia, uma saudade imensa ( 7 ) da ilha que fôra seu berço, celebrando-a mais tarde num sonêto famoso:

1) A itha de Zante era então posessão da República de Veneza. Para ter informaçōes sôbre Fóscolo, no Brasil, consultar: C. Tavares Bastos; Dante e outros Pootas Italianos na interpretação Brasileira, Rio de Janeiro, 1953, pgs. 185.186.

2) Fóscolo, além de literato e poeta, foi também militar e patriota. Seus escritos tiveram notável influência sôbre os homens do Ressurgimento italiano, em especial, sôbre Mazzini e Garibaldi.

3) O pai, André, médico e de sentimentos violentos, descendia de venezianos estabelecidos em Zante no século XVII; a mãe, Diamantina Spathys, era natural de Zante e de descen. dêneia grega. Fóscolo ufanava-se de ser descendente de duas estirpes - italiana e grega - que haviam culfivado tão esplêndidamente as artes e as letras.

4) Parte da Dalmácia pertencia, naquela época, aos domínios venezianos. Spálato, de 1420 até 1801, foi possessão da República de Veneza. Atualmente pertence à lugoslávia.

5) Rubina, Joāo morto suicida em 1801, e Júlio. Este último, antes oficial do exército na. poleônico e depois do austríaco, suicidou-se em 1838.

6- Fóscolo considerou-se veneziano e, portanto, italiano. A liberdade e a independência da Itália fôra seu ideal de patriota.

7) Ainda pouco tempo antes de morrer, o poeta pensava de voltar para Zante. 
Né piú mai toccherò le sacre sponde

Ove il mio corpo fanciulletto giacque.

Zacinto mia, che te specchi nell'onde

Del greco mar, da eui vergine nacque

Venere e fea quelle isole feconde

Col suo primo sorriso...

Tu non altro che il canto avrai del figlio,

O materna mia terra: a noi prescrisse

Il fato illacrimata sepoltura $\left(^{(}\right)$.

Em Veneza aprendeu a língua italiana, aprofundou-se nas línguas clássicas e estudou, também, os grandes autores modernos italianos e estrangeiros. Essa paixão literária nunca mais o deixou, apesar dos acontecimentos políticos e militares, no meio dos quais viveu, e das freqüentes e tempestuosas aventuras sentimentais, que deslustraram sua agitada e desafortunada existência.

Em Veneza, sua família vivia então na pobreza, de que fóscolo não se envergonhava e até se vangloriava. Sedento de liberdade, interessou-se logo pelos problemas políticos; levado pelo entusiasmo, liderava e inflamava com discursos plutarquianos grupos de moços que simpatizavam com as idéias revolucionárias vindas de França. Hostilizado pelo govêrno da República de Veneza, foi prêso por alguns meses; depois, obedecendo aos conselhos dos familiares, retirou-se, temporàriamente, para as colinas Eugâneas.

Começou a escrever ainda muito moço, atraindo a atenção dos circulas literários e dos homens de letras $\left({ }^{\circ}\right)$. Em 1787, foi representada no teatro Sant'Angelo $(19)$ a sua tragédia Tieste. $O$ êxito foi estrondoso e Fóscolo tornou-se improvisamente célebre. Tinha dezenove anos.

Aproximando-se os Franceses vitoriosos, Fóscolo vai a Bolonha, alista-se no exército napoleônico, volta a Veneza com as tropas francesas e torna-se um dos quatro secretários da Municipalidade, perorando a causa da liberdade da Itália junto de Napoleão. Mas as esperanças e o entusiasmo dos primeiros dias transformaram-se logo em desilusão e amargura. Napoleão acaba com a República de Veneza e cede seus territórios ao govêrno da Austria, em troca de van-

\footnotetext{
8) Sznéto A Zzcinto, $\checkmark v$. I- $\$ / 12.14$.

9) Dalmistro, Cesarotti, Pindemonte as culias damas Ranier Michiel e Isabella Teotochi.

10) Neste célebre teatro Goldeni havia representado suas comédias durante muitos anos.
} 
- tagens políticas ('). Desdenhoso, oprimido e pessimista, Fóscolo, desde então, ficará convencido de que a fôrça e a astúcia governam o mundo.

Para não viver debaixo dos Austríacos, Fóscolo vai a Milão ('2). Ali continua pregando seus ideais políticos de liberdade, escrevendo em jornais $\left({ }^{13}\right)$ que foram logo suprimidos pelas autoridades francesas.

Em 1798, Fóscolo trabalha em Bolonha, na Secção Criminal do Departamento do Reno. Mas, ao aproximar-se do exército austrorusso, que pretende invadir a Itália do norte, ocupada pelas tropas de Napoleão, Fóscolo volta às armas e luta ao lado dos Franceses contra os invasores $\left({ }^{14}\right)$.

Na qualidade de Lugar-Tenente da Guarda Nacional, combate em diversos lugares, desloca-se para cá e para lá, de conformidade com as exigências da guerra, indo acabar em Antibes, na França ${ }^{(15)}$. A vitória napoleônica de Marengo, porém, abre logo, também para Fóscolo, o caminho da volta à Itália. Estabelece-se em Milão, tomando parte, todavia, na campanha da Romanha e da Toscana. Em Florença continua sua atividade literária, voltando para Milão em 1801. No fim do mesmo ano, Fóscolo é profundamente amargurado pela notícia de que seu irmão João, tenente de infantaria, se havia suicidado, em Veneza. Entre dificuldades e decepções de tôda espécie ( ${ }^{(6)}$ ), vive e trabalha em Milão até o ano de 1804, quando vai à França para tomar parte na invasão da Inglaterra, que Napoleão estava preparando. Ocupa o tempo estudando inglês com Fanny Emeritt, da qual teve a filha Floriana. Entrementes, Napoleão abandona o plano do desembarque na Inglaterra, e Fóscolo consegue a licença de rever os familiares. Passando por Paris, volta à Itália e, depois de visitar os parentes em Veneza, está de nôvo em Milão, onde Cafarelli, ministro da guerra e seu amigo, dispensa-o das obrigações do serviço militar para atender às atividades literárias. Fóscolo trabalha intensamente, sempre lutando com dificuldades e problemas

11) No tratado de Campofórmio, em 1797, Napoleão cedeu à Austria Veneza e seus territórios.

12) Esta cidade, durante a primeira metade do século findo, tornara-se um dos centros culturais e patrióticcs mais importantes da ltália.

13) F scolo fci redator de II Monitore e foi um dos fundadores de L'Italiano.

14) Depsis da tratado de Campofórmio, Fóscolo compreendeu que Napoleão e os Franceses nāo tomavem a sério a causa da independência da Itália. Por consequinte não foram pou. cos es atritos entre êle as autoridades francesas No entanto, pensava que a ltália mais fàci'mente conseguiria a independência $\mathrm{ccm}$ a ajuda dos Franceses do que com a dos Austrícecs. A história posterior havia de mostrar que fóscolo estava certo.

15) Combateu em Cento, Novi e especialmente em Gênova.

16) Fóscolo publica, em 1802, o rcmance Ultime lettere di Ifcopo Ortis. A história, deveras singular, da composição e da publicaçāo desta obra se pode ler na edição Rizzoli, de 1949. 
diversos. Em 1807, publica o famoso carme Dei Sepolcri, cuja leitura desperta uma impressão enorme entre os literatos e os moços. Fóscolo havia assim granjeado fama universal de poeta. Consegue a cátedra de eloqüência na Universidade de Pavia (1809); suprimidas logo mais tôdas as cátedras de eloqüência por um decreto de Napoleão, o poeta volta a Milão, a braços com dificuldades econômicas. Em 1811, é apresentada no teatro La Scala a sua tragédia Aiace; foi um fracasso. Metido em polêmicas violentas, contra adversários políticos e literários $(1,2)$, o govêrno aconselha-o a afastar-se da cidade e concede-lhe uma licença de oito meses. Visita entăo os familiares, em Veneza, e depois vai a Bolonha e a Florença. Aqui vive dias relativamente serenos, entre amigos e literatos, conhece Fabre, que the faz o fomoso retrato, e leva para a frente o poema Le Grazie.

Mas fóscolo nunca devia ter paz e sossêgo. Em 1813 corre para Milão, onde a situação política e militar é muito perigosa por causa das derrotas de Napoleão. Quando o imperador cai nas mãos dos Inglêses, os Austríacos ocupam Milão e oferecem a Fóscolo a direção de um jornal e um bom ordenado. O poeta, cansado e desiludido, não querendo prestar juramento aos novos invasores da Itália, foge para a Suiça (1815), dando inicio ao seu exilio voluntário.

Passado algum tempo em Lugano, vagueia para cá e para lá, ałé se estabelecer em Zurique e, finalmente, em Hottingen. Sendo desalentadoras as noticias que chegavam da ltália, Fóscolo, na qualidade de cidadão de Zante, então sob protetorado inglês, consegue o passaporte para a Inglaterra e vai a Londres em 1816.

Na Inglaterra Fóscolo passa os últimos onze anos de vida.

Conhecido pelas suas abras literárias e pela sua hostilidade a Napoleão, o poeta foi bem recebido em Londres. Frequientando a casa de lord Holland, travou relaçōes cam homens de letras e políticos. Escreveu para revistas e editores ( $\left.{ }^{18}\right)$; mas suas condições econômicas eram precárias.

Em 1817, a notícia da morte da mäe, falecida em Veneza, entristeceu-o profundamente. Quando, em 1822, encontrou sua filha Floriana, um raio de esperança e de confôrto brilhou para Fóscolo. Com o património de Floriana construiu uma residência elegante, contraindo dividas que não conseguiu pagar. A casa foi pôsta em leilão pelos credores e para Fóscolo despontaram dias de sofrimento

17) Tensa e áspera fei a polèmica entre Fóscolo e Monti, antes amigos e depois adversobrios ferrenhos.

18) Escreveu para as revistas Edinburg Review, Now Monlly Magazine, European Royiew, pura os edirores Murray e Hebhouse. 
"e de miséria. Afastou-se de todos os amigos inglêses e, confortado pelo carinho de Floriana, viveu, adoentado, os últimos dias em Turnham Green, nos arredores de Londres, onde veio falecer paupérrimo, em 1827. Sepultado no cemitério de Chiswick, não foi esquecido pelos Italianos. Em 1871, a Itália, após ter alcançado a independência, tão almejada por Fóscolo, fêz transladar seus restos mortais para Florença, onde até hoje descansam na Igreja de Santa Cruz, que - poeta havia celebrado no carme Dei Sepolcri.

A imagem poética e a personalidade humana de fóscolo não ficariam devidamente esclarecidas e compreendidas, se não acrescentássemos algumas breves informações sôbre sua vida sentimental.

Muitas foram as mulheres $\left({ }^{19}\right)$ que despertaram seu entusiasmo afetivo e também suas paixões amorosas. Entretanto, o torvelinho dos acontecimentos e a natural instabilidade sentimental do poeta nunca the consentiram constituir um lar. Seja como fôr, acima das paixões sentimentais que o arrebataram, Fóscolo idealizou um tipo de mulher que vem mostrar um aspecto nobre de sua múltipla fenomenologia sensual. Segundo êle, a mulher reúne em si mesma tudo o que há de gentil e de luminoso nesta terra:

A áurea beldade em que tiveram

Alívio único aos males

As nascidas para tresvariar mentes mortais $\left({ }^{\circ}\right)$.

A virtuosa beleza da mulher, segundo Fóscolo, arrancou o homem da originária ferocidade e o sustentou na criação de um mundo gentil e de uma civilização luminosa. Portanto, a mulher ideal de Fóscolo é a fôrça esplendorosa que, tirando o homem animalesco das cavernas, torna-o gentil e o guia pelas sendas luminosas que constroem a civilização do gênero humano.

A idealização foscoliana da mulher é feifa, poèticamente, no poemeto Le Grazie $\left({ }^{21}\right)$, divindades intermédias entre os homens e os deuses; habitam elas sôbre a terra sem serem vistas, distribuem dons celestes, confortam e tornam mansos e gentis os Homens, educando-os "na idéia divina da beleza, no prazer da virtude e no estudo das artes".

19) Sôbre êste assunto escreveram especialmente: $M$. Saponaro, Vita amorosa ed eroica di Ugo Fóscolo, Milão, 1957; P. Schinetti, Fóscolo innamorato, Milão, 1927.

20) All'Amica risanata, vv. 10.12.

21) Para a ccmposição dêste poema fóscolo inspirou-se, parcialmente em Canova, que havia terminado a estátua de Vênus e estava trabalhando em tôrno do grupo de lo Grazie. 
2 - Atividade literária de Fóscalo.

A atividade literária de fóscolo foi extraordinária, se se considerar o teor de vida agilada que o poeta levou do berço até o túmulo.

Tão-sòmente para que fique ilustrada sua fecunda variedade literária, lembramos que seus escritos foram publicados numa coleção de doze volumes (2"), devida aos esforços de três estudiosos foscolianos de renome: F. S. Orlandini, E. Mayer, G. Chiarini.

I-IV: Prose letterarie.

V: Prose politiche.

VI-VIII: Epistalario.

IX: Poesie.

$X-X I$ : Saggi di critica storico-letteraria.

XII: Appendice.

Mencionamos apenas o titulo das obras principais.

Em poesia: Dei Sepolcri; Le Grazie; Canzoni; Sonetti; Odi.

Em prosa: Le ultime lettere di lácopo Órtis; Notizie intorno a Didimo Chierico; Lezioni di eloquenza; Lettera apologetica; Discorsi storici e saggi critici sulla letteratura italiana; Gazzettino del bel mondo; Epistolario.

Tragédias: Tieste; Aiace; Ricciarda.

Traduçōes: Viaggio sentimentale di Yorik, de L. Sterne; La chioma di Berenice, de Calimaco.

\section{3 - As Grandes llusóes, Fontes de Poesia e de Progresso.}

A rápida trajetória existencial e sentimental de Fóscolo, que mais acima traçamos, permite-nos tirar algumas conclusões que nos facultam compreender como o poela foi levado a formular a sua filosofia das grandes ilusões, fontes de poesia e de progresso para - gênero humano. Sempre guardou Fóscolo um amor profundo ao lar paterno, à mãe, aos irmãos, a Zante, à ltália, e almejou viver junto de seus entes queridos, desfrutando o carinho materno e os afetos familiares. No entanto, as vicissitudes históricas e seu desejo desenfreado de glória transformaram sua vida numa infinda seqüência de peripécias e de tristezas, numa odisséia familiar, porque a sorte

22) Arualmente está sendo publicada, na libilia, Ediça Nacional de iódos as obras da Fóscolo. 
- desenraizou para sempre da casa nativa e o condenou a uma contínua saudade da serenidade doméstica. Donde nasceu nêle a convicção de que os tão acarinhados e sonhados afetos domésticos não passam de uma doce ilusão.

Guerreou, escreveu e polemizou a vida tôda pela liberdade e pela independência da Itália, sua pátria de adoção $\left({ }^{23}\right)$. Não conseguiu, entretanto, ver realizado êste seu nobre ideal cívico. Teve uma vida errante e, pràticamente, sem pátria:

andrò sempre fuggendo

di gente in gente $\left({ }^{24}\right)$.

Ma io deluse a voi le palme tendo,

E sol da lunge i miei tetti saluto ${ }^{(25)}$.

E quando viu baldadas tôdas as esperanças, foi para o exillio. Diante disso, também a pátria pareceu-lhe uma nobre ilusão. Muitas mulheres despertaram seu entusiasmo afetivo e ao longo de sua torturada existência nunca abandonou a esperança de concretizar o seu sonho de amor. E no entanto, acossado sempre pelos acontecimentos, levado pelo seu temperamento irrequieto,

- Avverso al mondo, avversi a me gli eventi... $\left({ }^{26}\right)$

E me che i tempi ed il desío d'onore

Fan per diversa gente ir fuggitivo... $\left({ }^{27}\right)$

nunca conseguiu realizar seu sonho afetivo e formar um lar. De sorte que, também a beleza, o amor, os afetos desvaneceram como puras ilusões.

Alcançou fama e glória literária ainda moço; mas, na verdade, conhecia muito bem a infelicidade que the atenazava o coração e

Quello spirto guerrier ch'entro mi rugge $\left({ }^{28}\right)$.

Viu ñascer, brilhar e morrer a estrêla gloriosa de Napoleão; conhecia, porém, sôbre quantos cadáveres, lágrimas, sangue e infâmias se erguia aquela glória. Portanto, a conclusão a que chegava a fria razão era a de que a glória não passava de uma sublime ilusão.

23) Para Fóscolo, Veneza fazia purte da Itális, cuja indspendência scmpre almejou.

24) Scnêto In morte del fratello Giovanni, vi. 1.2.

25) Idem, ibidem, vv. 7-8. Citamos o texio da redaçāo primitiva do scnêto.

26) Ssnêto Ritrztto di se stesso, v. 7.

27) Dei Sepolcri, vv. 26-27.

28) Sinêto Alla sera, v. 14 . 
Havia nascido Fóscolo numa família cristã; a mãe era mulher de fina inteligência e de sinceros sentimentos religiosos. Quando menino, passou algum tempo no seminário de Spátalo, viveu no meio de uma sociedade que professava o catolicismo, foi amigo do abade Ãngelo Dalmistro e teve profunda estima e admiração pelo abade Parini $\left({ }^{29}\right)$. Apesar disto, Fóscolo, sob a influência da filosofia anglofrancesa de Setecentos, mecanicista, sensualista e materialista, bem como diante do quadro selvagem de guerras e revoluçōes, pràticamente negadoras de todos os valores pregados pelo cristianismo, concluiu por uma interpretação mecanicista do universo e parece ter visto sòmente o nada além da vida dèste mundo. Segundo êle,

$\ldots .$. involve

Tutte cose l'oblio nella sua notte;

E una forza operosa le affatica

Di moto in moto; el'uomo e le sue tombe

E l'estreme sembianze e le reliquie

Della terra e del ciel traveste il tempo $\left({ }^{30}\right)$.

Afinal, para Fóscolo, tôdas as coisas

Vanno al nulla eterno... (3)

Vero è ben, Pindemonte! Anche la Speme, Ultima Dea, fugge i sepoleri ( ${ }^{32}$ ).

A imortalidade da alma é uma das grandes ilusães, a última e a mais sublime, que o homem inventa. A unica imortalidade possivel para o homem é a de viver na memória da posteridade. Contudo, no espírito de fóscolo permanece a aspiraçāo ideal à imortalidade objetiva, conforme a entendem a religião e o pensamento tradicional.

O tormento espiritual de Fóscolo decorre da contradição, em que o poeta ficou enleado, entre mecanicismo e finalismo, entre materialismo e espiritualismo. Não caiu êle num pessimismo apático, porém, nem se abandonou a uma estéril melancolia, nem se suicidou como o Ortis de seu romance; lutou com energia extraordinária e procurou uma justificação para a vida e para a ação. Sim, parece dizer Fóscolo, o amor, o heroismo, os afetos domésticos, a glória, a

29) Parini é lembrado com edmirasão no remance Ultime lettere di lf́copo Órtis e celebrado no carme Dei Sepoleri.

30) Dei Sepolcri, vv. 17.22.

3i) Sonêto Alla sers, v. 10.

32) Dei Sepoleri, vv. 16-17. Pindemente foi amigo de Fóscolo, que a èle dedicou o carme Dei Sepolkri. 
pátria, a poesia, a imortalidade, afinal todos os grandes valores, pelos quais o gênero humano vive e combate, não passam de ilusões. Mas é preciso acreditar nestas sublimes ilusões, temos que lutar a fim de realizá-las; nós vivemos por elas e para elas. Destarte, o gênero humano é impulsionado para a ação e vai construindo, ao longo de sua história, o luminoso caminho de sua civilização. E verdade que os magnânimos ideais humanos não passam de sublimes ilusões, mas é preciso ter fé nêles, porque, destarte, o homem tem a fôrça espiritual para realizar com plenitude vital o progresso da humanidade. Sem a fé nestas grandes ilusões, o homem cairia fatalmente numa inércia mortal, que o levaria à barbárie primitiva. Com base nesta filosofia das grandes ilusões, Fóscolo mergulhou-se com ardor e coragem na ação, tomou parte tempestuosamente nos acontecimentos de seu tempo.

A grande poesia de Fóscolo inspira-se nessa filosofia. Como na época foscoliana, assim na atual e em qualquer outra, há homens que não fazem interpretações espirituais do universo, e, por conseguinte, lutam continumente pela realização daqueles ideais que $\circ$ poeta chamou de "grandes e sublimes ilusões". Para êsses homens a poesia de fóscolo é um alento para a ação e sôbre êles exerce uma fascinação vital.

\section{4 - Sua Mensagem Fóscolo expressou, poèticamente, no carme \\ Dei Sepolcri.}

Fóscolo, chegado a esta interpretação filosófica do destino humano, a expressou, poèticamente, no carme Dei Sepolcri. "Os Sepolcri são o retrato de Fóscolo, são, sobretudo, a consagração poética de uma nobre e triste religião da civilização e da vida" $\left.{ }^{(33}\right)$.

Partindo de premissas mecanicistas da filosofia inglêsa e francesa de Setecentos, Fóscolo pensou "ser o mundo governado por uma fôrça desconhecida e operosa, que transforma perpètuamente, inelutàvelmente $o$ homem $e$ as coisas. A vida pareceu-lhe infelicidade para todos e, além da existência nesta terra, parece ter visto sòmente o nada. Aceitou a vida assim como êle a imaginava, cheia de tormentos e de alegrias, e acreditou nas grandes ilusões, as únicas coisas que confortam e empolgam a existência. Não tem importância se não as conseguimos concretizar ;a esperança nos acompanha até o túmulo e ali construímos, segundo Fóscolo, a última e mais perfeita ilusão, a da imortalidade.

33) Attílio MOMIGLIANO, História da Literatura ltaliana; tradução de Luiz WASHINGTON e Antônio D’ELIA, São Paulo, 1948, p. 316. 
Precisamente em virtude desta ilusão, há lugar uma celeste correspondência de sentimentos afetuosos entre os vivos e os mortos, e o túmulo, conservando a memória dos homens bons e famosos, impulsiona os homens para a vida virtuosa" $\left({ }^{34}\right)$. Destarte, as sublimes ilusōes se tornam fôrças motoras que propulsam o progresso humano.

Uma grave áura, um sentimento melancólico circundam o poema, e uma atmosfera meditativa e desolada, mas nảo desesperada, exala dos túmulos e os envolve, numa solidão cósmica fascinante e ao mesmo tempo angustiosa.

"Do princípio até o fim, da abertura solitária sôbre as sombras dos ciprestes e das urnas confortadas pelo pranto, ao encerramento sôbre as campas interrogadas pelo cego imortal - Homero -, sôbre todo o carme se estende a religiosa paz de um cemitério. E em tôda parte os pensamentos e as imagens detêm a alma do leitor nesse lugar que é sagrado mesmo para quem não conhece o confôrto de Deus; e parece que um espírito magnânimo ali celebre, em nome da humanidade presente, a humanidade desaparecida" $\left({ }^{35}\right)$.

Um sentimento melancólico e soberbo ao mesmo tempo envolve o carme do coméço até o fim, dando-lhe um fascínio singular. 0 sentimento melancólico e desolado é gerado pela convição de que o tempo destrói tôdas as coisas e pelo conceito de uma imortalidade que não é a sobrevivência da alma humana num mundo ignoto; 0 sentimento soberbo e solene origina-se da convicção de que o homem vive imortal na memória das geraçōes futuras, graças à lembrança que os túmulos nelas despertam. A poesia, celebrando os túmulos, eterniza na memória dos que vivem as obras magnânimas dos heróis. Destarte o mortal consegue arrancar-se à morte e entregar-se à imortalidade. Sim, nós perecemos completamente; há, porém, em nós a ilusão de continuar a viver depois da morte no pensamento vígil e lembrador dos que nos amam.

Os túmulos familiares despertam nos parentes e aviventam nos amigos afetos carinhosos para com os mortos, que vivem, destarte, no coração dos vivos:

\section{Celeste è questa}

Corrispondenza d'amorosi sensi,

Celeste dote è negli umani; e spesso

Per lei si vive con l'amico estinto

34) Rosário TOSTO. Histório da L'teratura iraliana; traduça de Luigi CASTAGNOLA, Petrópolis. 1963, vol. III, p. 41.

35) A. MOMIGLIANO, cit., D. 317. 
El'estinto con noi, se pia la terra

Che lo raccolse infante e lo nutriva,

Nel suo grembo materno ultimo asilo

Porgendo, sacre le reliquie renda

Dall'insultar de' nembi e dal profano

Piede del vulgo, e serbi un sasso il nome,

E di fiori odorata àrbore amica

Le ceneri di molli ombre consoli $\left({ }^{36}\right)$.

Por sua vez, os heróis vivem na memória dos povos, graças aos túmulos que perpetuam a lembrança das grandes obras que deixaram e incitam as novas gerações a realizar coisas magnânimas.

A egregie cose il forte animo accendono

L'urne de' forti, o Pindemonte; e bella

E santa fanno al peregrin la terra

Che le ricetta $\left({ }^{37}\right)$.

E verdade que o tempo destrói também os túmulos; mas, quando isto acontecer, levantam-se as Musas e comovem os poetas que celebram com seus hinos os heróis. $E$ não há fôrça destruidora que possa fazer calar o canto alto das Musas:

Siedon custodi de' sepolcri, e quando

Il tempo con sue fredde ale vi spazza

Fin le rovine, le Pimplée fan lieti

Di lor canto i deserti, e l'armonia

Vince di mille secoli il silenzio $\left.{ }^{38}\right)$.

Um timbre viril sustenta a melancolia do carme, que é "o canto mais magnânimo da ltália" $\left({ }^{39}\right)$. Vastas imagens de vida e de morte se entrelaçam ao longo de todo o poema, que tem por cenário a vastidão da história e a imensidão da terra, ora iluminada pelo sol, bela de vegetação e de animais, ora semelhante a um campo semeado de ossos sem fim.

O carme, composto de 295 hendecassilabos soltos $\left({ }^{40}\right)$, começa com uma pergunta desconsolada. "As tumbas, confortadas pelas sombras dos ciprestes e pelos prantos dos vivos, tornam, porventura, menos desconsolado o sono da morte? Para Fóscolo, a resposta de-

36) Dei Sepolcri, vv. 29-40.

37) Dei Sepoleri, vv. 151-154

38) Doi Sepolcri, vv. 230-234.

39) A. MOMIGLIANO, cit., p. 318.

40) De conformidade com a terminolegia métrica em uso na Itália. 
via ser negativa: os mortos nāo têm mais desejos e recordaçōes, não provam mais nem alegria nem dor, porque, perdida a vida e apagada e esperança, os mortais, como tôdas as coisas, voltam ao seio da natureza. Os sepulcros são inúteis aos mortos; contudo à fria razão se opōem o sentimento e a fé em um ideal de sobrevivência, necessários um e outra para que o homem viva e aceite a morte sem maldizê-la. E uma ilusão, sim, mas benéfica, sôbre a qual se funda a religião dos túmulos, nascida por um contrato social e transmitida com ritos diversos entre todos os povos. $E$, na verdade, não vivem de certo modo também os mortos, se atrás de si deixam uma herança de afetos e os vivos recordam e admiram suas obras? Celeste é tal privilégio, e as tumbas têm a tarefa de estabelecer esta amorosa ligação entre aquêles que se foram e os que ficam. Só os maus não fazem questão dos túmulos, porque morrem completamente, logo que cala para êles a harmonia do dia. Não a alma é imortal, pensa Fóscolo, mas a memória que de nós permanece sôbre a terra. Se fizermos algo de grande não morreremos nunca, porque as Musas são as filhas da Memória e têm o dom de prolongar no tempo a existência humana. Iniqua é, portanto, a lei (" $\left.{ }^{4}\right)$ que subtrai os sepulcros à piedade dos homens, e, em nome de uma impossível igualdade, quer misturar os túmulos dos maus e dos bons, dos grandes e dos infames. Nem existe maior sinal de decadência civil e política do que o abandono ao qual a cidade de Milão, corrupta e esquecida, deixou o túmulo de Parini.

Desde quando a instituição da família, do estado e da religião fêz com que os homens se respeitassem a si mesmos e aos outros, êles sepultaram os mortos, honrando aquêles que as virtudes domésticas ou o amor pela pátria tinha consagrado à glória perene; nem, no variar de épocas ou de costumes, cessou aquêle culto. Se o costume de sepultar os mortos nas igrejas merece reprovação de um ponto de vista higiênico e pelo efeito deprimente que exercem os esqueletos efigiados sôbre lajes tumbais, belo é, ao contrário, o uso dos povos antigos, renovado agora pelos Inglêses, de sepultá-los em jardins, à sombra dos ciprestes e dos cedros, entre flôres e águas purificadoras.

\section{Cipressi e cedri,}

Di puri effluvi i zèfiri impregnando,

Perenne verde protendean su l'urne

Per memoria perenne, e prezïosi

Vasi accogliean le lagrime votive.

41) Fóseclo slude a lei francesa que o édiro de S. Claud devia esiender ambém à Itália. 
Rapían gli amici una favilla al Sole

A illuminar la sotterranea notte

Perché gli occhi dell'uom cercan morendo

II Sole; e tutti l'ultimo sospiro

Mandano i petti alla fuggente luce.

Le fontane versando acque lustrali

Amaranti educavano e vïole

Su la funebre zolla; e chi sedea

A libar latte 0 a raccontar sue pene

Ai cari estinti, una fragranza intorno

Sentia qual $d^{\prime}$ aura de' beati Elisi $\left({ }^{42}\right)$.

Mas onde, como na Itália, não existe o amor pela virtude e pela glória, inúteis são os monumentos fúnebres. Todavia a Itália não foi sempre serva. Das tumbas de seus grandes, sepultados na Igreja de Santa Cruz $\left({ }^{43}\right)$, levanta-se o aviso severo para pensar e agir altamente, bem como a esperança de uma futura ressureição.. Tudo tem sido tirado aos Italianos, mas não foi apagada a recordação da grandeza passada; e isto soube Alfiéri, que, desgostoso com os vivos, encontrava inspiração e confôrto na companhia daqueles mortos. Agora dorme com êles e seus ossos fremem de amor pela pátria. Se um dia os Italianos haverão de ressurgir, aquelas tumbas os inflamarão. Do mesmo modo, os Gregos pelos túmulos de Maratona eram incitados a amar a liberdade e a aborrir os bárbaros.

\section{Ah sí! da quella}

Religiosa pace un Nume parla:

E nutría contro a' Persi in Maratona, Ove Atene sacrò tombe a' suoi prodi, La virtù greca e l'ira $\left({ }^{44}\right)$.

Os grandes mortos falam aos vivos que são dignos e os educam para fortes paixões e nobres empreendimentos. Se as tumbas e os lugares que as guardam estão sujeitos à ação do tempo destruidor, o ensinamento dêles não cala, porque vive eterno no canto dos poetas. A poesia, mais do que os túmulos, celebra as glórias passadas e as transmite à posteridade. Se, depois de tantos séculos, os homens descobriram na Tóade inculta o sepulcro de 110 , isto se deve ùnicamente a Homero. O grande vate, interrogando as urnas solitárias,

42) Dei Sepolcri, vv, 114-129.

43) Neste templo florentino estão sepultados alguns dos homens mais famosos da Itália. Fóscolo, no carme, menciona Maquiavel, Miguel-Ångelo, Galileu, Alfiéri.

44) Dei Sepolcri, vv. 197.201. 
cantou, é verdade, a glória dos Gregos vencedores, mas também a dos Troianos vencidos, e, mais do que a fôrça de Aquiles, o heroismo desventurado de Heitor" $\left({ }^{45}\right)$.

E tu onore di pianto, Ettore, avrai Ove fia santo e lagrimato il sangue Per la patria versato, e finché il Sole Risplenderà su le sciagure umane ( $\left.{ }^{40}\right)$.

45) Rosáris TOSTO, História da Literatura Italiana; tradusajo de Lulgi CASTAGNOLA. Petró. poiis, 1983, vol. I11, pp. 51-52.

46) Dei Sepoleri, vr. 292-295. 